\title{
Immunopathogenesis of COVID-19 and early immunomodulators
}

\author{
Kyung-Yil Lee, MD, PhD ${ }^{1,2}$, Jung-Woo Rhim, MD, PhD ${ }^{1}$, Jin-Han Kang, MD, PhD ${ }^{1}$ \\ ${ }^{1}$ The Catholic University of Korea College of Medicine, Seoul, Korea; ${ }^{2}$ Junglock Biomedical Institute, Daejeon, Korea
}

The novel coronavirus disease 2019 (COVID-19) is spreading globally. Although its etiologic agent is discovered as severe acute respiratory syndrome coronavirus-2 (SARS-CoV-2), there are many unsolved issues in COVID-19 and other infectious diseases. The causes of different clinical phenotypes and incubation periods among individuals, species specificity, and cytokine storm with lymphopenia as well as the mechanism of damage to organ cells are unknown. It has been suggested that in viral pneumonia, virus itself is not a direct cause of acute lung injury; rather, aberrant immune reactions of the host to the insults from viral infection are responsible. According to its epidemiological and clinical characteristics, SARS-CoV-2 may be a virus with low virulence in nature that has adapted to the human species. Current immunological concepts have limited ability to explain such unsolved issues, and a presumed immunopathogenesis of COVID-19 is presented under the proteinhomeostasis-system hypothesis. Every disease, including COVID-19, has etiological substances controlled by the host immune system according to size and biochemical properties. Patients with severe pneumonia caused by SARS-CoV-2 show more severe hypercytokinemia with corresponding lymphocytopenia than patients with mild pneumonia; thus, early immunomodulator treatment, including corticosteroids, has been considered. However, current guidelines recommend their use only for patients with advanced pneumonia or acute respiratory distress syndrome. Since the immunopathogenesis of pneumonia may be the same for all patients regardless of age or severity and the critical immune-mediated lung injury may begin in the early stage of the disease, early immunomodulator treatment, including corticosteroids and intravenous immunoglobulin, can help reduce morbidity and possibly mortality rates of older patients with underlying conditions.

Key words: COVID-19, Pathogenesis, Protein-homeostasis-system hypothesis, Corticosteroids, Intravenous immunoglobulin

\section{Introduction}

The novel coronavirus disease 2019 (COVID-19), caused by severe acute respiratory syndrome coronavirus-2 (SARS-CoV-2), has spread globally since the first fatal cases were reported in Wuhan, China, and the World Health Organization declared it a pandemic on March 11, 2020. ${ }^{1)}$ Although the epidemiological and clinical characteristics of COVID-19 are still manifesting, early reports indicate that the majority of patients experience mild symptoms without pneumonia but that a small proportion suffers from severe pneumonia, which can progress to acute respiratory distress syndrome (ARDS), multiple organ failure, and death, especially in older patients with underlying diseases such as diabetes and cardiovascular disorders. ${ }^{2-4)} \mathrm{A}$ milder clinical course, including asymptomatic infection, is common in children and young adults, although individuals in these age groups can experience severe pneumonia. ${ }^{5)}$

Including the causes of the appearance of different clinical phenotypes among individuals, many questions remain regarding the pathophysiology of COVID-19. For example, where does viral replication occur during the incubation period and why does this period differ among patients? How do viruses induce organ cell injury? Is the novel coronavirus more virulent than other coronaviruses such as severe acute respiratory syndrome coronavirus (SARS-CoV)? How does cytokine storm affect entire lung tissues, and which cytokines are responsible? Why does lymphopenia occur and what is the role of lymphocytes? When will this pandemic resolve? As with many other human diseases, the physiopathology of COVID-19 is poorly understood.

The host immune system reacts not only to substances derived from infectious pathogens, such as pathogen-associated molecular patterns (PAMPs) and other toxins, but also to substances derived from injured or infected host cells as a result of infectious insult, including damage (danger)-associated molecular patterns (DAMPs), particularly in cases of intracellular pathogen infections such as COVID-19.6-9) Every disease has etiologic substances, but current immunological concepts have limited ability to explain the pathogenesis of many diseases, including

Corresponding author: Kyung-Yil Lee, MD, PhD. Department of Pediatrics, The Catholic University of Korea Daejeon St. Mary's Hospital, 64 Daeheung-ro, Jung-gu, Daejeon 34943, Korea 
COVID-19. Thus, new hypotheses are needed to settle unsolved issues in biomedicine.

This review discusses unresolved issues in our understanding of infectious diseases and SARS-CoV-2 infection and possible mechanisms of acute organ cell injury in COVID-19 are discussed through the lens of the protein-homeostasis-system (PHS) hypothesis. Given that uncontrolled extensive immune reactions may be a leading cause of COVID-19 fatalities, a rationale for early immune-modulator treatment is presented for clinicians concerned about the potential complications of corticosteroid treatment in older patients with underlying conditions.

\section{Biological characteristics of coronaviruses}

\section{Taxonomy and replication of viruses}

Coronaviruses viruses have a positive-sense single-stranded RNA genome of approximately 27-34 kilobases and belong to the Coronaviridae family. Coronaviruses affect mainly mammals and birds; to date, 7 subtypes, including SARS-CoV-2, are known in humans. Human coronaviruses 229E, OC43, NL63, and HKU1 cause mild respiratory tract infections in the form of the common cold, with rare cases manifesting as severe pneumonia. SARS-CoV and Middle East respiratory syndrome coronavirus (MERS-CoV) can cause serious respiratory tract infections, although the majority of infected patients recover completely. ${ }^{10-12)}$ Coronaviruses attach to complementary host cell receptors, and viral RNAs and viral structural proteins are replicated using nonstructural proteins such as polyproteins, RNA-dependent RNA polymerase, and the host cell's ribosomes. Viral RNA and structural proteins are then assembled into progeny viruses. Among the abundant viral RNAs synthesized in virus-infected cells, including 7-10 specific viral mRNAs, only full-length genomic RNA is packaged. Virus-infected cells contain larger numbers of various virus-originating proteins and viral RNAs than the number of intact virions by a factor of $10^{3}-$ $10^{4} .{ }^{13)}$ Host cell-originating immune proteins such as interferons and immune peptides against invading pathogens and other cell contents are also found in the cells. The clinical manifestations of some viral infections, such as measles, are reportedly associated with viremia from the secondary focus, such as regional lymph nodes. ${ }^{14)}$ Therefore, viremia can be defined as the spreading of viruses and related substances.

The entire genomic sequence of SARS-CoV-2 has been reported, upon which reverse transcription polymerase chain reaction (RT-PCR) diagnostic tools have been developed. ${ }^{15,16)}$ RNA viruses can easily exchange RNA within a host and species and possibly across species, like influenza viruses, but how extremely minor changes in structural or nonstructural proteins can induce different levels of virulence and clinical phenotypes in different target-cell injuries are not understood. Also unknown is which viral proteins are immunogenic or pathogenic to host cells. Inactivated intact viruses, attenuated live viruses, viral proteins, and viral nucleic acids have been used for vaccine development, ${ }^{17}$ ) suggesting that these materials can be immunogenic but not pathogenic to a host's organ cells.

\section{Clinical aspects and infected cells}

Although the focus, i.e., the location of initial infected cells in the respiratory tract, and how many cells are infected are not yet known, viruses and substances derived from infected cells can direct their way to the inside of the host as bacterial commensals in microbiota do on occasion. Clinical manifestations and disease severity depend on the amounts of these diverse substances. The infected patients with little or less amounts of these substances may experience asymptomatic or mild infections and can recover rapidly from the disease. Thus, patients after asymptomatic or mild infections can produce a negative result on RT-PCR but a positive result on serology. RT-PCR results can be positive in SARS-CoV-2 carriers after asymptomatic or mild infections. Further, since virus culturing and/or paired immunoglobulin G (IgG) testing is a standard method for confirming viral infection, not all RT-PCR-positive patients may be contagious.

Despite the similarity of structural proteins across speciesspecific viruses, the primary affected organ cells differ among host animals. Humans and chickens suffer most often from respiratory tract cell injury, whereas cows and pigs are affected mainly by gastroenteric cell injury. In influenza virus infections, lower respiratory cells are mainly affected in human and mammals and enteric cells in birds. ${ }^{13,18)}$ It is unlikely that all affected organ cells are initially virus-infected, since there are few intact viruses in pathologic lesions of affected organs. ${ }^{19,20)}$ Some patients with COVID-19 experience extrapulmonary manifestations, such as gastrointestinal dysfunction, loss of taste and smell, the exacerbation of underlying diseases such as cardiovascular disorders, and other organ involvements. ${ }^{21-23)}$ Interestingly, during this pandemic, cases of severe Kawasaki disease (KD)like disease, temporally named "multisystem inflammatory syndrome in children (MIS-C)" have been reported in large cities in Western countries, but not in East Asian countries such as Japan and Korea, where KD is endemic. Children affected by MIS-C are older and manifest shock syndrome with acute heart failure, gastroenteric symptoms, and other symptoms like KD. ${ }^{24,25)} \mathrm{It}$ is unknown whether the disease is associated with SARS-CoV-2 or other pathogens related to the changed environment such as school closure caused by COVID-19. Early intravenous immunoglobulin (IVIG) and corticosteroids appear to effectively lead to early recovery from the disease as shown in $\mathrm{KD} .{ }^{24,25)}$

Along with different clinical manifestations, infected patients have differing incubation periods. It is possible that different substances may be produced according to the infected cell, such as upper respiratory epithelial cells versus the regional lymph node cells or lower respiratory endothelial cells. Because the intracellular environment differs among infected cells, the timing and direction of the expulsion of viruses and related substances can also differ. Accordingly, viruses and substances in upper respiratory epithelial cells are easily discharged outside the host, while those in regional lymph node cells or lower respiratory 
endothelial cells are discharged inside the host. Occasional reported cases of SARS or COVID-19 relapse ${ }^{26}$ can be explained by this hypothesis. However, it is unknown whether a superspreader of viruses has specific cells that rapidly replicate complete virions.

\section{Coronaviruses and microbiota}

Microbiota consist of bacteria, viruses, and fungi in the host's oropharynx and lower respiratory tract, gastrointestinal tract, skin, and urogenital tract. ${ }^{27)}$ Normal bacterial flora or commensals in microbiota ecosystems may have evolved with their host and become critical elements of the host's immune system. ${ }^{28)}$ Disruption of the collaborative relationship between the microbiota and the host (dysbiosis) is an important subject in the medical field, although the majority of previous studies have focused on the bacterial microbiota. ${ }^{29,30)}$ Despite the homeostatic balance between commensals and the host, some commensals can invade and induce immune reactions that lead to infectious diseases such as acute pyelonephritis, acute otitis media and pneumonia, and postinfectious immune-mediated diseases such as $\mathrm{KD},{ }^{31,32)}$

Coronaviruses may have evolved approximately 8,000 years ago, and the most recent common ancestor of coronaviruses in mammals, birds, and humans has been described. ${ }^{33)}$ Although viruses in the microbiota of humans have received less research attention, viruses and human species almost certainly coevolved toward a symbiotic relationship. Approximately $8 \%$ of the human genome may be related to ancient viral genomes, and in the microbial world, certain bacteriophages (viruses of bacteria) can kill bacteria, whereas other bacteriophages have a symbiotic relationship with the same bacterial hosts. ${ }^{34)}$ Coronavirus infections occur every year with seasonal predominance as common viral infections in childhood, ${ }^{35)}$ and each outbreak can be initiated by carriers whose viruses have adapted to the host as the normal flora. Because equilibrium between the microbiota and a host's immune system is constantly evolving such as by the turning of pathogens into normal constituents of the host's microbiota, the majority of infected patients with adapted pathogens, even younger children with no immunity to a new strain, may be mildly symptomatic or asymptomatic. In this pandemic, infants, neonates, and even fetuses of mothers infected with SARSCOV-2 may have uneventful outcomes. ${ }^{5,36,37)}$ Since the delicate and complex viral replication processes may not be performed by order or information from the viral genome, it is possible that a host may help replicate adapted viruses within certain cells, and viruses may evolve the ability to expel their progeny outside, rather than inside, the host through the engagement of a low-virulent nature as normal flora in the host. Initially severe infectious diseases, including pandemic influenza, scarlet fever, Korean hemorrhagic fever, and infection-related immunemediated diseases such as $\mathrm{KD}$ and Henoch-Schönlein purpura (HSP), have become less severe over time in Korea. ${ }^{38-40)}$ These phenomena suggest that disease phenotypes can change as the pathogens adapt to the human species over time.
Coronaviruses are species-specific across mammals and birds, as are other viruses and pathogens such as influenza viruses and mycoplasma species. This may be a result of a symbiotic relationship between the species and the adapted virus. Considering their epidemiological characteristics such as a lack of stable carriers in humans, it is possible that zoonotic avian influenza viruses, SARS-CoV and MERS-CoV may not be adapted viruses though human-to-human transmission is possible. In the COVID-19 pandemic, there may be competition among adapted strains for predominance in the microbiota, or adaptive viruses may require a new strain to maintain themselves in the microbiota of the host species.

\section{Coronaviruses and herd immunity}

Common childhood respiratory viral infections caused by respiratory syncytial viruses, rhinoviruses, influenza viruses, and coronaviruses may occur annually with 3- to 4-year interval outbreaks, and nationwide outbreaks of Mycoplasma pneumoniae (MP) pneumonia and measles prior to the vaccine era have occurred at intervals of $3-4$ years. ${ }^{41)}$ Therefore, the majority of older children and adults developed immunity to the pathogens through previous infections whereas a subset of individuals, especially young children, remained susceptible. Alternatively, herd immunity to a pathogen is established in populations.

Because animal studies have used several animal-passaged viruses to attenuate viral virulence, ${ }^{42)}$ it is possible that individuals infected with viruses that have passed through several persons late in this pandemic may be less symptomatic than those infected earlier. Herd immunity such as cross-immunity obtained from previous coronavirus infections may be responsible for the reported virulence of SARS-CoV-2. For example, during the $1918 \mathrm{H} 1 \mathrm{~N} 1$ influenza pandemic, individuals of all ages may have been infected, but the highest reported mortality rate was among those 20-40 years of age. During the 2009 H1N1 influenza pandemic, children and adults $<40$ years of age were mainly affected with febrile symptoms, whereas those $>41$ years of age were relatively protected from symptomatic influenza with low mortality rates compared with the 1918 pandemic. ${ }^{43,44)}$ Between the 2 pandemics, there was the 1968 H2N3 Hong Kong influenza pandemic just 40 years before the 2009 pandemic. Collectively, these findings suggest that a cross-reactive herd immunity across adapted influenza viruses regardless of serotype may develop in humans. ${ }^{44)}$ On the other hand, the results of studies on the seroprevalence of crossreactive antibodies prior to the 2009 pandemic differ somewhat across populations, but the antibody positivity rates do not differ significantly across all adult groups, ${ }^{45)}$ suggesting the presence of pre-existing herd immunity not detectable by cross-reactive antibodies. ${ }^{44,46)}$ In the early stage of the current pandemic, the mortality rate was higher among older adult groups and might appear to vary among populations. It is unknown at the present time whether the age distribution of all infected patients could differ over time or if the herd immunity obtained from previous coronavirus outbreaks could affect the mortality rates of the 
older age groups among populations. Severe symptoms may be rare due to the cross-reactive immune status obtained from other coronavirus infections at a young age, which is more likely to persist in children and young adults than in older adults.

Epidemiological data on all infected patients during outbreaks can help scientists estimate the potential of herd immunity development to pathogens and predict future progression of the pandemic. In Korea, during the 2009 H1N1 pandemic, approximately $1.5 \%$ of the total population $(\sim 740,000 /$ $49,000,000)$ reportedly had RT-PCR-proven febrile symptoms; of them, a total of 225 patients died for a mortality rate of $0.03 \%{ }^{47)}$ The mortality rate of the 2009 pandemic was higher in older patients ( $>65$ years) with underlying diseases despite infection rates being far lower than those of other age groups and might have been lower than the annual seasonal influenza. Postpandemic serologic studies have reported that $40 \%-60 \%$ of the population, especially young children and young adults, may be asymptomatic or have only mild infection. ${ }^{46,48)}$

COVID-19 data from children are current sparse, but infants reportedly show more severe symptoms. ${ }^{5,49)}$ Although thorough quarantine protocols can delay the spread to children, it is expected that most children will become infected with this adapted virus. The majority of patients may be asymptomatic or mildly symptomatic, but some children can be afflicted with severe pneumonia. Young children easily become carriers for long periods and acted as reservoirs during epidemics of MP pneumonia, seasonal influenza, and possibly SARS-CoV-2 infection. ${ }^{50,51)}$

It is unknown when this pandemic will fade. From an evolutionary perspective, this will occur when the new pathogen reaches a symbiotic relationship with the host species. Given that persistent or periodic outbreaks are initiated by carriers and the events are the only method for progeny spread, this may be possible when enough stable carriers are established in the human species despite existing and developing herd immunity.

\section{Coronaviruses and immune reaction}

\section{Host immune evolution}

Multicellular organisms, including human beings, likely evolv. ed from single-cell organisms in which toxic substances were extremely small, and the protection system may be an intracellular adapted system that consists of immune proteins and peptides such as antimicrobial peptides (AMPs). Multicellular organisms, in contrast, are constructed of many organs, and each organ cell is separated and protected by cell membranes, has different receptors, and produces different proteins. The immune systems of various organisms may have evolved to protect their cells at the molecular level. Plants and insects, which evolved far earlier than mammals, still have only innate immune systems. ${ }^{52,53)}$ In insects such as the fruit fly, the major immune mechanism consists of phagocytes with Toll receptors and immune protein systems against external and possibly internal insults including pathogens and natural toxins. ${ }^{53)}$ It is believed that external insults from natural sources such as toxins and pathogens may not change at a rate sufficient to allow a new immune system to evolve in mammals and other animal species. Furthermore, the innate immune system of mammals can effectively remove external pathogens, including viruses, bacteria, and fungi, if the pathogens cannot hide themselves within the host's cells. Small substances derived from pathogens such as PAMPs and biochemicals can induce immune reactions through Toll-like receptors (TLRs) similar to Tolls in insects. Therefore, the adaptive immune system of mammals may have evolved against mainly internal insults, including the dysbiotic state of microbiota since mammals are composed of different organ cell types and microbials in the microbiota. Besides the invasion of numerous microbials in the microbiota, each organ cell can produce countless immunologically active substances, including pathogenic proteins and peptides. Given that mammalian immune systems may have evolved to protect self-cells from exposure to toxic cellular components from other self-cells, it is possible that one of the major functions of apoptosis, autophagy, DNA traps of immune cells, and epigenetic changes such as gene methylation within cells may perform this critical role. ${ }^{54)}$

Because communication across cells is required to maintain a healthy state in multicellular species, this task involves the production of signalling substances in certain cell lines and receptors on other cells. All human diseases may have etiological or triggering substances of disease onset, ranging from extremely small materials, such as elements or monoamines, to larg. er materials, such as bacteria and parasites. The former category includes carbon monoxide, nicotine, and chemicals (or drugs) with an affinity for the receptors expressed on or in host cells. ${ }^{55,56)}$ In infectious diseases, viruses and bacteria themselves are not direct toxins to host cells; rather, it is the smaller substances produced by infectious insults that may be responsible for cell injury. ${ }^{54}$

\section{DAMPs and etiological substances from infected cells}

DAMPs are substances produced by cells injured in various events, including infection and trauma. Well-studied intracellular DAMPs include high mobility group box-1 (HMGB-1), S100 proteins, and heat-shock proteins. ${ }^{57)}$ DAMPs can bind to TLRs or intracellular sensors of innate immune cells or affected cells in a similar manner to PAMPs. Binding DAMPs to patternrecognition receptors on innate immune cells can induce proinflammatory cytokines and other proteins that influence adaptive immune cell functions, such as the determination of T-cell subtypes and autoantibody production. ${ }^{57,58)}$ Recently, interest in DAMPs has grown in the medical field. Elevated levels of intracellular protein DAMPs, such as HMGB-1, S100 proteins, and heat-shock proteins, have been reported in infectious diseases, immune-mediated diseases, cancers, and neurologic diseases. ${ }^{59-61)}$

In addition to DAMPs and pathogen-derived substances including PAMPs, numerous unidentified inflammation-inducing 
intracellular substances exist. Clinical observations suggest that substances from certain organ-specific cells can injure cells in the same or in other organs. Severe pneumonia and ARDS can be caused by nonpathogen-associated insults such as blunt chest contusion, gastric content aspiration, multiple injuries, multiple transfusions, burns, pancreatitis, near-drowning, inhalation of toxic gas, and amniotic fluid embolism. ${ }^{62)}$ Rhabdomyolysis can be caused by the measles virus, influenza viruses, and coronaviruses, ${ }^{63,64)}$ and substances produced by injured muscle cells may be responsible for arrhythmia, acute kidney injury, and other problematic conditions. Orchitis (or oophoritis), a complication of the mumps, generally appears after swelling of the parotid glands, ${ }^{65)}$ suggesting that orchitis-inducing substances may originate in injured parotid gland cells. Sympathetic ophthalmia occurs when a traumatic injury to one eyeball induces inflam. mation in other healthy eye. ${ }^{66}$ Similarly, cerebral contusions can induce abrupt cerebral edema of nearly all neuronal cells of the cerebrum and can induce longer morbidity consisting of complications such as seizure. ${ }^{67)}$ In HSP, skin purpuric vasculitis appears mainly in pressured areas such as the buttocks and lower extremities and can be easily elicited by mild external pressure such as a tourniquet test. ${ }^{68)}$ The initiation of joint symptoms may be related to minor physical trauma at the affected joints such as the knees and hips in many patients with juvenile idiopathic arthritis or other adult arthropathies, including osteoarthritis. ${ }^{69)}$ These findings suggest that the affected vascular or joint cells in HSP and arthritis may be vulnerable to inflammation as a result of mild physical trauma. Therefore, in viral pneumonia, substances from initially infected cells and those from lung cells affected or injured by immune-mediated insults can induce further inflammation in neighboring lung tissue cells and possibly other organ tissue cells.

\section{PHS hypothesis}

A theory or hypothesis is needed to increase our understanding of the pathogenesis of various diseases. We presented the PHS hypothesis to explain the pathogenesis of the diseases, including all infectious diseases, influenza, MP pneumonia, ARDS, KD, and all kidney diseases including genetic diseases and cancers. 19,54,62,70-72) In the PHS hypothesis, the adaptive immune system controls pathogenic or etiological protein substances using a recombination of immune genes for B-cell receptors (BCRs) and T-cell receptors (TCRs); B cells control pathogenic proteins through antibody production, and $\mathrm{T}$ cells control pathogenic peptides, possibly through TCR-related immune reactions. The innate immune system controls larger substances such as intact viruses, bacteria, and apoptotic bodies through phagocytes, while smaller non-protein substances such as polysaccharides, viral DNAs, and viral RNAs are controlled through TLRs, natural antibodies, complements, and other immune protein systems.

The PHS hypothesis presents new interpretations of some unsolved immunological observations. Etiological substances of disease have variable sizes and biochemical characteristics and originate from external sources or internal sources, such as from injured or infected cells. Therefore, immune cells and immune proteins seen in pathologic lesions such as neutrophils, T cells, natural killer (NK) cells, immunoglobulins, and complements are not acting by nonspecific or bystander immune stimuli such as chemokines, but rather for the purpose of host cell protection from pathogenic substances as needed in the host. Given that numerous kinds of peptides, including peptide hormone, AMPs, and intracellular peptides in proteasomes, play critical roles in the lives of organisms, as do proteins, neuropeptides, and monoamines in vivo, ${ }^{73-75)}$ it is reasonable to assume that the main function of T cells is to control pathogenic peptides that hurt or signal the host's target cells. ${ }^{54)}$ Injuries to target cells in autoimmune diseases may not be caused by specific antibodies or specific $\mathrm{T}$ cells against the antigens expressed on self-cells but rather by persistent aberrant immune reactions of nonspecific adaptive immune cells to substances produced by injured selfcells. The etiology of genetic diseases and cancers may involve a transformed protein or a protein deficiency in organ tissue cells or within a cell; adapted reactions such as the production of alternative or compensatory proteins in the PHS may be responsible for disease development and progression due to long-term nonspecific hyperactive reactions associated with these proteins. A "cancer organ" consists of cancer cells and normal vascular and other supportive cells of the host. In certain cancers, cancer cells may communicate with host immune cells such as macrophages and possibly $\mathrm{T}$ cells that have receptors for cross-talk. Blocking communication between cancer cells and immune cells can, therefore, suppress cancer cell growth. ${ }^{72)}$ Certain diseases, including idiopathic nephrotic syndrome, or central nervous system diseases such as prion diseases and Alzheimer disease, exhibit no adaptive immune cells or immune proteins such as immunoglobulins and complements in the initial pathologic lesions. The etiological substances in these diseases may be the size of neuropeptides. The innate immune system, which is composed of undefined immune proteins or immune peptides, may control these substances. ${ }^{72)}$

\section{Presumed immunopathogenesis of COVID-19}

Based on clinical and pathologic characteristics of the disease and the PHS hypothesis, the pathogenesis of acute or chronic lung injury in COVID-19 is as follows. During the incubation period, substances that can induce injuries to lung cells and possibly other organ cells are produced by SARS-CoV-2-infected cells as the focus of initiation of the disease. The potentially toxic or signalling substances spread systemically and locally and then bind to receptors on the target organ cells that have an affinity for them. To control various sized substances at the early stage of COVID-19, innate immune system cells and proteins such as neutrophils, macrophages, NK cells, immune proteins, and possibly immune peptides, as well as nonspecific T cells and $\mathrm{B}$ cells (nonspecific antibodies), may comprise the first-line effec- 
tors since specific immune reactions take at least several days or more to take effect due to the immune gene recombination of TCRs and BCRs. The clinical symptoms of COVID-19 such as fever, myalgia, and pneumonia begin to appear at this stage. The cytokine storms in rapidly progressive severe COVID-19 and other infectious diseases ${ }^{76,77)}$ may be associated with excessive immune cell activations against large amounts of substances at this stage.

In the case of pneumonia, the target cells may be lower respiratory tract cells, possibly respiratory endothelial cells, while the main etiologic substances may be pathogenic peptides since numerous $\mathrm{T}$ cells infiltrate pathologic lesions in lungs with corresponding peripheral lymphopenia. At the first stage, rapid and first-line immune responses are elicited by innate and nonspecific adaptive immune reactions, including nonspecific $T$ cell, possibly cytotoxic T-cell activation, NK cell activation, antibodydependent cytotoxic reaction, and/or complement system pathway activation. However, the initial immune reaction may be somewhat crude and less effective across the immune network, and the imbalanced cytokine network caused by excess proinflammatory cytokines and proteolytic enzymes may ensue, which may be related to target lung cell injury, which can induce fibrin leakage to the alveolar space and thromboembolitic insults. In the second stage, the substances derived from injured target cells or the changed circumstances caused by the initial insult induce further inflammation of the neighboring lung tissue cells with corresponding immune cells and immune proteins. Secondary bacterial invasion through broken lung barriers can induce further lung tissue inflammation, which may overwhelm the host's immune system. After the appearance of specific T cells and specific antibodies (B cells), inflammatory substances, including the pathogenic proteins and peptides, are effectively controlled and inflammation processes may cease (Fig. 1).

Some patients with pneumonia may delay or fail to induce specific immune cell clones against pathogenic proteins or peptides derived from infected or injured organ cells, and the ongoing activation of nonspecific adaptive immune cells with high levels of proinflammatory cytokines may be responsible for further injury of neighboring cells and other organ cells, resulting in a vicious cycle and manifesting chronic pulmonary diseases or chronic extrapulmonary complications. Because the prognosis for pneumonia depends on the ability of a host's immune system to control both the initial substances and the diverse substances from target cells injured by initial insults, early control of initial lung cell injury and possibly initial other organ cell injury, is crucial to preventing disease progression.

The immune system of neonates matures and acquires a memory as the host grows and ages. The innate immune system
A

B

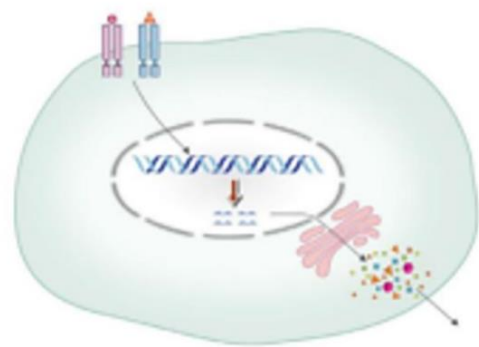

C

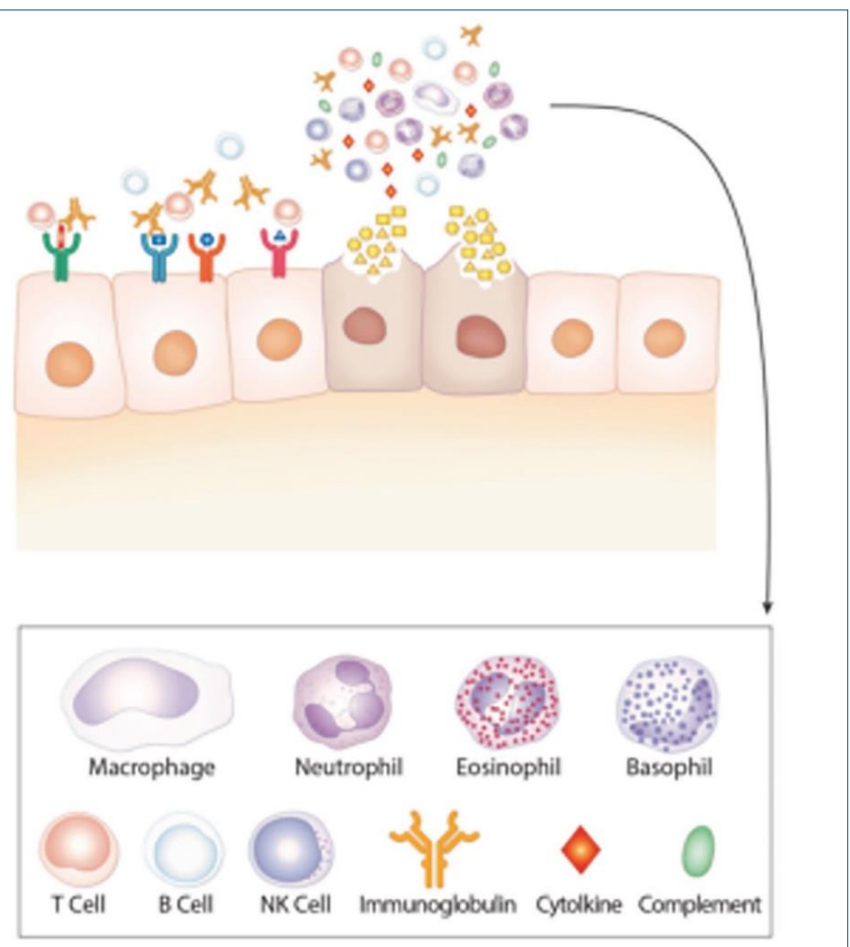

Fig. 1. A presumed pathogenesis of acute lung injury in the novel coronavirus disease 2019 (COVID-19). During the incubation period, the severe acute respiratory syndrome coronavirus-2 virus replicates within certain host cells and numerous substances are produced, including replicated virions, pathogenorigin substances such as pathogen-associated molecular patterns and by-products, and host cell-origin substances such as damage (danger)-associated molecular patterns, immune proteins, pathogenic proteins, and pathogenic peptides. These substances spread via the local or systemic circulation when infected cells are destroyed (A). Among these substances, pathogenic peptides or other substances bind to the receptors on target lung cells, which can be directly toxic to the target cells or signal to immune cells via other proteins produced by the target cells (B). First, activation of nonspecific T cells and other immune cells and/or an aberrant cytokine imbalance induces target-cell injury. Then, substances from injured lung cells and the subsequent bacterial invasion induce further inflammation with corresponding activation of immune cells and immune proteins (C). Once specific T-cell and B-cell clones (specific antibodies) appear to control pathogenic proteins and peptides, the tissue injury ceases. The specific immune cell responses to cellular injury may be delayed or absent in some patients with COVID-19, leading to chronic lung diseases, other organ diseases, or even death. NK, natural killer. 
of neonates is relatively compatible with that of adults, while adaptive immune systems such as thymus size, white blood cell level with lymphocyte differentials, and immunoglobulin (Ig) G, IgM, IgA, and IgE levels may mature with age. ${ }^{78,79)}$ Younger children with infectious diseases such as hepatitis A, SARS, and MP pneumonia and those with infection-related immunemediated diseases such as KD and acute poststreptococcal glomerulonephritis experience less severe clinical symptoms than older children and young adults. ${ }^{80-82}$ As intact virion clearance depends primarily on the innate immune system, ${ }^{19)}$ an immature or developing adaptive immune system may be less responsive against initial immune-mediated insults on target cells.

Older patients with underlying diseases show more severe outcomes in COVID-19 as well influenza, SARS, and hemolytic uremic syndrome caused by toxin-producing Escherichia coli. ${ }^{83,84)}$ Infectious diseases such as influenza and COVID-19 can exacerbate underlying chronic diseases, including diabetes, cardiovascular diseases, asthma, chronic obstructive pulmonary disease, and chronic hepatic or renal insufficiency. ${ }^{85,86}$ Older patients with underlying diseases may lack the numerical capacity of the immune cells to respond to pathologic lesions since the host's immune cells are also acting against the insults from active underlying diseases. Conversely, acute exacerbation of underlying diseases, especially immune-mediated diseases such as type 1 diabetes or immune-mediated cardiovascular disorders, may be caused by the mobilization of immune cells to new battlefields, which can result in a fatal outcome of otherwise mild cases of pneumonia. Older patents have higher ery. throcyte sedimentation rates and C-reactive protein levels than younger patients, suggesting that immune activation was ongoing at presentation in cases of $2009 \mathrm{H} 1 \mathrm{~N} 1$ influenza. ${ }^{44)} \mathrm{In}$ elderly individuals, the natural weakness of immune functions such as the production of immune cells to eliminate virions and substances from initial viremia and the recombination of specific immune cell clones may less be effective. ${ }^{87)}$ In addition, pneumonia itself may be a major risk factor since initial immune-mediated lung cell injuries can induce further inflam. mation and secondary bacterial invasion. Some patients show an atypical and slow disease progress, which can delay the diagnosis of pneumonia. ${ }^{88)} \mathrm{A}$ large proportion of patients who succumb to viral pneumonia have commensal invasions, including Staphylococcus aureus, Streptococcus pneumoniae, Streptococcus pyogenes, and rarely gram-negative bacteria despite the preventive use of antibiotics. ${ }^{89)}$

In infectious diseases, antipathogen $\operatorname{IgM}$ and following $\operatorname{IgG}$ antibodies typically begin to appear at 3-4 days or more after disease onset. ${ }^{90)}$ A plasma cell clone produces specific antibodies for only one protein, which can bind BCRs, and a specific T-cell clone can do the same for only one peptide. Thus, antigens that induce pathogen-specific antibodies are not whole virions but rather fragments of virus proteins derived from infected cells or fragments from antigen-presenting cells that engulf entire virions. In SARS, some patients with severe pneumonia have a prolonged seroconversion period, and pneumonia can further progress to ARDS despite the appearance of antiviral antibodies. ${ }^{91)}$ It is possible that the patients may have few intact virions at the initial focus, and the fragments or by-products from the replication processes in the infected cells can induce immune reactions that are responsible for inflammation and target-cell injury. Individuals who acquired cross-reactive neutralizing antibodies to the $\mathrm{H} 1 \mathrm{~N} 1$ virus can be infected with influenza during the $2009 \mathrm{H} 1 \mathrm{~N} 1$ pandemic as previously mentioned. ${ }^{44,46}$ Patients who received two-time mumps-measles-rubella vaccines can be affected by mumps and measles, presenting with IgG antibody positivity and less severe symptoms at the early disease stage. ${ }^{92,93)}$ These findings suggests that both antipathogen antibodies and other immune substances may be needed to prevent infectious diseases and alleviate clinical symptoms.

\section{Treatment}

In this review, we focus on immune modulators because the pathogenesis of viral pneumonia is not a virus-induced cytopathy but rather an immune reaction of the host against infectious insults. Viral diseases, including COVID-19, are self-limiting, meaning that the host's immune system can theoretically control the insults without complications. However, a small proportion of COVID-19 patients experience progression of the disease or complications, such as severe progressive pneumonia and ARDS. Thus, clinicians and researchers are searching for treatment modalities to prevent disease progression and complications. Due to a lack of data on antivirals for children, study groups recommend that outpatients and hospitalized patients with mild or moderate COVID-19 could be managed with supportive care, including herbal medicine. ${ }^{94,95)}$

As previously suggested, the immunopathogenesis of COVID may involve 2 stages of disease progression: first, target-cell injury caused by aberrant immune reactions against substances from infected cells; and second, further target and other cell injuries caused by substances from target-cell injury and/or secondary bacterial invasion. During immune responses to viral insults, all host immune cells may communicate with each other via cytokine networks and major histocompatibility complexes. ${ }^{54)}$ Therefore, diverse immune proteins, including interleukin (IL)-1, IL-6, and tumor necrosis factor-alpha, and other cytokines and immune proteins may be involved in inflammatory processes in COVID-19 and other immune-mediated diseases. Blocking one of the inflammatory pathways could reduce inflammation and result in clinical improvement. Therefore, antivirals, interferons, immune-modulating drugs such as hydroxychloroquine, biologics for cytokines, antisera obtained from recovered patients, and other anti-inflammatory drugs may effectively im. prove morbidity in patients with COVID-19 by reducing the inflammation-inducing substances or altering the disease process. However, these drugs, including high-dose corticosteroids and IVIG, have a limited effect on advanced ARDS because they cannot resolve the excess inflammation-inducing substances 
associated with target-cell injuries and insults from secondary bacterial invasion. The host's immune system cannot call up soldiers into the extensively extended battlefields. There have been few well-designed randomized controlled trials for these drugs and no proven effective drugs for improving mortality. ${ }^{96,97)}$

Aberrant or hyperimmune reactions of the host against infectious insults such as cytokine storm are part of the immunopathogenesis of pneumonia and ARDS caused by various pathogens, including SARS-CoV, influenza viruses, and Streptococcus pneumoniae. ${ }^{62,98-100)}$ Thus, immune modulators, corticosteroids in particular, have been used to treat severe pneumonia or ARDS. Although numerous studies, including those of SARS-CoV and influenza, have been conducted, the effects of corticosteroid are inconclusive due to multiple confounding factors; the timing, dose, and schedule of corticosteroid therapy and the selected subjects differed across study groups. ${ }^{19,62,101,102)}$ Furthermore, there have been few studies of early pre-emptive corticosteroid use for the purpose of reducing morbidity or mortality. ${ }^{19,62)}$

We reported that early systemic immunomodulators such as corticosteroids and/or IVIG with antibiotics or antivirals can halt the progression of pneumonia and induce the rapid recovery of pulmonary lesions in patients with influenza virus or MP infections. ${ }^{103-107)}$ In MP pneumonia, MP considered one of the smallest bacterial species, is extremely sensitive to antibiotics such as macrolides, tetracyclines, and quinolones in vitro. However, some patients exhibit progressive pneumonia despite adequate antibiotic treatment. We have suggested that the pathogenesis of lung injury in MP pneumonia is similar to that of viral pneumonia, and antibiotics may have a limited effect on MP infection. ${ }^{70,107,108)}$ Earlier corticosteroid treatment is more effective at reducing morbidity and preventing pneumonia progression as shown during 4 MP pneumonia epidemics in recent decades. ${ }^{105-107)}$ Also, patients with severe pneumonia caused by SARS-CoV-2 show high levels of various cytokines that are associated with disease severity as seen in influenza, MP pneumonia infection, and SARS. ${ }^{109)}$ We recommended administering immunomodulators (corticosteroids) as soon as possible to severe pneumonia patients with COVID-19. ${ }^{110)}$ Although many study groups have suggested or reported on the early use of immunomodulators including corticosteroids, ${ }^{111-113)}$ few studies have examined early corticosteroid use for severe pneumonia patients during the pandemic.

Studies of the early use of corticosteroids in adult patients with severe community-acquired pneumonia (CAP) also reported that early corticosteroid therapy administered within 24 or 36 hours can help reduce morbidity and treatment failure. ${ }^{14,115)}$ The majority of patients in these series are older individuals with underlying conditions such as diabetes and cardiovascular diseases. Although hyperglycemia was more common in the treated patients, it can be controlled with insulin therapy. The number of patients requiring treatment in intensive care units and/or with mechanical ventilation can also be reduced. ${ }^{115)} \mathrm{A}$ meta-analysis of 10 randomized controlled studies of patients with severe CAP reported that adjunctive corticosteroid treatment showed favorable outcomes such as reduced all-cause mortality, septic shock, and the requirement for mechanical ventilation without increasing the risk of adverse events. ${ }^{116}$ ) Such efforts to reduce morbidity are expected to ease health care workloads and prevent medical care system collapse.

Because the severity of ongoing diseases is associated with corresponding immune reactions and the effect of immunomodulators is dose-dependent, higher doses may be needed for patients with severe pneumonia. In addition, because specific adaptive immune cells may begin to appear within a week, rapid tapering of corticosteroids within a week may be necessary to avoid the acute suppression of normally acting immune cells. ${ }^{62)}$ This treatment policy, based on the PHS hypothesis, provides a rationale for early immune-modulator treatment of infectious or infection-related immune-mediated diseases that can elicit acute or subacute whole-organ destructive diseases including myocarditis, rapidly progressive glomerulonephritis, fulminant hepatitis, necrotizing pancreatitis, acute adrenal insufficiency (Waterhouse-Friderichsen syndrome), extensive epidermolysis, and acute encephalopathy. ${ }^{62)}$

Corticosteroids and/or IVIG may achieve the early stabilization of aberrant immune reactions performed by a host's entire immune system and especially nonspecific adaptive immune cells, as they can be considered host cell-originating substitutes including cortisol and serum IgG. ${ }^{62)}$ The beneficial effects of corticosteroid on various infectious diseases, including viral infections such as Epstein-Barr virus infection and infectious croup as well as severe bacterial infections such as tuberculous meningitis and typhoid fever, are well known. Furthermore, methylprednisolone pulse therapy $(30 \mathrm{mg} / \mathrm{kg} /$ day or $1 \mathrm{~g} /$ day for adults) is used for 3 or more consecutive days for severe infectious disease and immune-mediated diseases such as MP pneumonia, lupus nephritis, $\mathrm{KD}$, acute central nervous system diseases, and even advanced chronic kidney diseases, ${ }^{117,118)}$ although the diseases are rare in older individuals. During this pandemic, some organ transplant recipients treated with T-cell suppressants seem to be protected from pneumonia, ${ }^{119)}$ and older patients receiving anticancer drugs can recover from severe COVID-19. ${ }^{120)}$ ARDS patients treated with corticosteroids and convalescent plasma show the rapid resolution of pneumonia lesions and clinical improvement. ${ }^{121,122)}$ The convalescent plasma contains antibodies against viral fragments and other antibodies and possibly anti-peptides against etiological and inflammation-inducing substances. Thus, it is possible that IVIG can act as a part of the convalescent sera against pathogenic proteins.

Taken together, early, short-term corticosteroids with/without IVIG, even at higher doses, may not seriously influence the preexisting immune status of many older patients with comorbidities. Although the immune status of patients affected with underlying conditions is critical, the late diagnosis and treatment of pneumonia may also have greater influence on outcomes in such patients. 


\section{Conclusion}

The etiologic agent of COVID-19 is SARS-CoV-2, but many issues in COVID-19 as well as other infectious diseases remain unresolved. To further increase our understanding of the issues, including the pathogenesis of COVID, we discussed the issues and proposed a mechanism of acute organ cell injury in COVID19 using the PHS hypothesis. Pneumonia patients infected with SARS-CoV-2 show hypercytokinemia with corresponding lymphopenia in the early disease stage; thus, early immune modulators are necessary. However, the guidelines recommend the use of corticosteroids only for patients with advanced pneumonia or ARDS. This policy may be unwarranted since the immunopathogenesis of pneumonia may be the same for all patients regardless of severity or age and the critical immune-mediated lung injury begins in the early stage of COVID-19.

Based on the PHS hypothesis and our previous experiences with viral infections such as influenza, acute bronchiolitis, and MP pneumonia, a rationale for early corticosteroid treatment was presented. Corticosteroids may exert a direct influence on whole-host immune systems and induce early stabilization of aberrant immune reactions on lung injury in COVID-19. We hope that this article will be helpful for clinicians, researchers, health care workers, and administrators tasked with responding to this ongoing pandemic disease.

\section{Conflicts of interest}

No potential conflict of interest relevant to this article was reported.

\section{References}

1. World Health Organization. Coronavirus disease 2019 (COVID-19) Situation Report-53 [Internet]. Geneva (Switzerland): World Health Organization; 2020 Mar [cited 2020 Apr 3]. Available from: https:// www.who.int/docs/default-source/coronaviruse/situation-reports/20200 313-sitrep-53-covid-19.

2. Deng SQ, Peng HJ. Characteristics of public health responses to the coronavirus disease 2019 outbreak in China. J Clin Med 2020;9:E575.

3. Park PG, Kim CH, Yoon H, Kim TS, Park CW, Kim CH. Out-of-hospital cohort treatment of coronavirus disease 2019 patients with mild symptoms in Korea: an experience from a single community treatment center. J Korean Med Sci 2020;35:e140.

4. Ciotti M, Angeletti S, Minieri M, Giovannetti M, Benvenuto D, Pascarella S, et al. COVID-19 outbreak: an overview. Chemotherapy 2020;7:1-9.

5. Dong Y, Mo X, Hu Y, Qi X, Jiang F, Jiang Z, Tong S. Epidemiology of COVID-19 among children in China. Pediatrics 2020;145:e20200702.

6. Beutler BA. TLRs and innate immunity. Blood 2009;113:1399-407.

7. Matzinger P. The danger model: a renewed sense of self. Science 2002; 296:301-5.

8. Land WG. The role of damage-associated molecular patterns in human diseases: part I promoting inflammation and immunity. Sultan Qaboos Univ Med J 2015;15:e9-e21.

9. Thomas J, Pociute A, Kevalas R, Malinauskas M, Jankauskaite L. Blood biomarkers differentiating viral versus bacterial pneumonia aetiology: a literature review. Ital J Pediatr 2020;46:4.
10. Demmler GJ, Ligon BL. Severe acute respiratory syndrome (SARS): a review of the history, epidemiology, prevention, and concerns for the future. Semin Pediatr Infect Dis 2003;14:240-4.

11. Hui DS, Azhar EI, Kim YJ, Memish ZA, Oh MD, Zumla A. Middle East respiratory syndrome coronavirus: risk factors and determinants of primary, household, and nosocomial transmission. Lancet Infect Dis 2018;18:e217-27.

12. Park SE. Epidemiology, virology, and clinical features of severe acute respiratory syndrome -coronavirus-2 (SARS-CoV-2; Coronavirus Dis ease-19). Clin Exp Pediatr 2020;63:119-24.

13. Fehr AR, Perlman S. Coronaviruses: an overview of their replication and pathogenesis. Methods Mol Biol 2015;1282:1-23.

14. de Vries RD, Mesman AW, Geijtenbeek TB, Duprex WP, de Swart RL. The pathogenesis of measles. Curr Opin Virol 2012;2:248-55.

15. Coronaviridae Study Group of the International Committee on Taxonomy of Viruses. The species severe acute respiratory syndrome-related coronavirus: classifying 2019-nCoV and naming it SARS-CoV-2. Nat Microbiol 2020;5:536-44.

16. Park WB, Kwon NJ, Choi SJ, Kang CK, Choe PG, Kim JY, et al. Virus isolation from the first patient with SARS-CoV-2 in Korea. J Korean Med Sci 2020;35:e84.

17. Vetter V, Denizer G, Friedland LR, Krishnan J, Shapiro M. Understanding modern-day vaccines: what you need to know. Ann Med 2018;50:11020.

18. Shao W, Li X, Goraya MU, Wang S, Chen JL. Evolution of influenza A virus by mutation and re-assortment. Int J Mol Sci 2017;18:1650. https:// doi.org/10.3390/ijms18081650.

19. Lee KY, Rhim JW, Kang JH. Hyperactive immune cells (T cells) may be responsible for acute lung injury in influenza virus infections: a need for early immune-modulators for severe cases. Med Hypotheses 2011;76:649.

20. Yao XH, Li TY, He ZC, Ping YF, Liu HW, Yu SC, et al. A pathological report of three COVID-19 cases by minimally invasive autopsies. Zhonghua Bing Li Xue Za Zhi (Chinese) 2020;49:E009.

21. Lechien JR, Chiesa-Estomba CM, De Siati DR, Horoi M, Le Bon SD, Rodriguez A, et al. Olfactory and gustatory dysfunctions as a clinical presentation of mild-to-moderate forms of the coronavirus disease (COVID-19): a multicenter European study. Eur Arch Otorhinolaryngol 2020 Apr 6 [Epub]. https://doi.org/10.1007/s00405-020-05965-1.

22. Mao L, Jin H, Wang M, Hu Y, Chen S, He Q, et al. Neurologic manifestations of hospitalized patients with coronavirus disease 2019 in Wuhan, China. JAMA Neurol 2020 Apr 10 [Epub]. https://doi.org/10.1001/ jamaneurol.2020.1127.

23. Cheng Y, Luo R, Wang K, Zhang M, Wang Z, Dong L, et al. Kidney disease is associated with in-hospital death of patients with COVID-19. Kidney Int 2020 March 19 [Epub]. https://doi.org/10.1016/j.kint.2020.03.005.

24. Verdoni L, Mazza A, Gervasoni A, Martelli L, Ruggeri M, Ciuffreda M, et al. An outbreak of severe Kawasaki-like disease at the Italian epicentre of the SARS-CoV-2 epidemic: an observational cohort study. Lancet 2020 May 13 [Epub]. https://doi.org/10.1016/S0140-6736(20)31103-X.

25. Belhadjer Z, Méot M, Bajolle F, Khraiche D, Legendre A, Abakka S, et al. Acute heart failure in multisystem inflammatory syndrome in children (MIS-C) in the context of global SARS-CoV-2 pandemic. Circulation 2020 May 17 [Epub]. https://doi.org/10.1161/CIRCULATIONAHA. 120.048360

26. Chen D, Xu W, Lei Z, Huang Z, Liu J, Gao Z, et al. Recurrence of positive SARS-CoV-2 RNA in COVID-19: a case report. Int J Infect Dis 2020;93:297-9.

27. Pulvirenti G, Parisi GF, Giallongo A, Papale M, Manti S, Savasta S, et al. Lower airway microbiota. Front Pediatr 2019;7:393. https://doi. org/10.3389/fped.2019.00393.

28. Belkaid Y, Hand TW. Role of the microbiota in immunity and inflammation. Cell 2014;157:121-41.

29. Lee KY, Hamada H, Arvonen M. Editorial: Infection-related immunemediated diseases and microbiota. Front Pediatr 2020;8:108. https://doi. org/10.3389/fped.2020.00108.

30. Marchesi JR, Adams DH, Fava F, Hermes GD, Hirschfield GM, Hold 
$\mathrm{G}$, et al. The gut microbiota and host health: a new clinical frontier. Gut 2016;65:330-9

31. Lee KY. New insights for febrile urinary tract infection (acute pyelonephritis) in children. Child Kidney Dis 2016;20:37-44.

32. Rhim JW, Kang HM, Han JW, Lee KY. A presumed etiology of Kawasaki disease based on epidemiological comparison with infectious or immunemediated diseases. Front Pediatr 2019;7:202. https://doi.org/10.3389/ fped.2019.00202

33. Cui J, Li F, Shi ZL. Origin and evolution of pathogenic coronaviruses. Nat Rev Microbiol 2019;17:181-92.

34. Zimmer C. A planet of viruses. Chicago (IL): University of Chicago Press, 2011.

35. Heimdal I, Moe N, Kokstad S, Christensen A, Skanke LH, Nordbø SA, et al. Human coronavirus in hospitalized children with respiratory tract infections: a 9-year population-based study from Norway. J Infect Dis 2019;219:1198-206.

36. Latif Panahi, Marzieh Amiri, Somaye Pouy. Clinical characteristics of COVID-19 infection in newborns and pediatrics: a systematic review. Arch Acad Emerg Med 2020;8:e50.

37. Schwartz DA. An analysis of 38 pregnant women with COVID-19, their newborn infants, and maternal-fetal transmission of SARS-CoV-2: maternal coronavirus infections and regnancy outcomes. Arch Pathol Lab Med 2020 Mar 17 [Epub]. https://doi.org/10.5858/arpa.2020-0901-SA.

38. Quinn RW. Comprehensive review of morbidity and mortality trends for rheumatic fever, streptococcal disease, and scarlet fever: the decline of rheumatic fever. Rev Infect Dis 1989;11:928-53.

39. Kil HR, Yu JW, Lee SC, Rhim JW, Lee KY. Changes in clinical and laboratory features of Kawasaki disease noted over time in Daejeon, Korea. Pediatr Rheumatol Online J 2017;15:60.

40. Rhim JW, Lee YT, Kang HM, Suh JS, Lee KY. Changes in clinical features in Henoch-Schönlein purpura during three decades: an observational study at a single hospital in Korea. Clin Rheumatol 2019;38:2811-8.

41. Kim EK, Youn YS, Rhim JW, Shin MS, Kang JH, Lee KY. Epidemiological comparison of three Mycoplasma pneumoniae pneumonia epidemics in a single hospital over 10 years. Korean J Pediatr 2015;58:172-7.

42. Wyde PR, Couch RB, Mackler BF, Cate TR, Levy BM. Effect of low- and high-passage influenza virus infection in normal and nude mice. Infect and Immun 1977;15:221-9.

43. Falagas ME, Koletsi PK, Baskouta E, Rafailidis PI, Dimopoulos G, Karageorgopoulos DE. Pandemic A(H1N1) 2009 influenza: review of the Southern Hemisphere experience. Epidemiol Infect 2011;139:27-40.

44. Rhim JW, Go EJ, Lee KY, Youn YS, Kim MS, Park SH, et al. Pandemic 2009 H1N1 virus infection in children and adults: a cohort study at a single hospital throughout the epidemic. Int Arch Med 2012;5:13.

45. Korea Centers for Disease Control and Prevention. Serologic cross-reactivity of serum samples from different age groups in Korea against a novel influenza A (H1N1) virus. Public Health Wkly Rep 2009;2:744-5.

46. Dudareva S, Schweiger B, Thamm M, Höhle M, Stark K, Krause G, et al. Prevalence of antibodies to 2009 pandemic Influenza A (H1N1) virus in German adult population in pre- and post-pandemic period. PLoS One 2011;6:e21340.

47. Kim JH, Yoo HS, Lee JS, Lee EG, Park HK, Sung YH, et al. The spread of pandemic H1N1 2009 by age and region and comparison among monitoring tools. J Korean Med Sci 2010;25:1109-12.

48. Chen CJ, Lee PI, Chang SC, Huang YC, Chiu CH, Hsieh YC, et al. Seroprevalence and severity of 2009 pandemic influenza A H1N1 in Taiwan. PLoS One 2011;6:e24440.

49. Ludvigsson JF. Systematic review of COVID-19 in children shows milder cases and a better prognosis than adults. Acta Paediatr 2020;109:108895 .

50. Dorigo-Zetsma JW, Wilbrink B, van der Nat H, Bartelds AI, Heijnen ML, Dankert J. Results of molecular detection of Mycoplasma pneumoniae among patients with acute respiratory infection and in their household contacts reveals children as human reservoirs. J Infect Dis 2001;183:675-

51. Choi SH, Kim HW, Kang JM, Kim DH, Cho EY. Epidemiology and clinical features of coronavirus disease 2019 in children. Clin Exp Pediatr
2020;63:125-32.

52. Muthamilarasan M, Prasad M. Plant innate immunity: an updated insight into defense mechanism. J Biosci 2013;38:433-49.

53. Cooper D, Eleftherianos I. Memory and specificity in the insect immune system: current perspectives and future challenges. Front Immunol 2017; 8:539.

54. Lee KY. A common immunopathogenesis mechanism for infectious diseases: the protein-homeostasis-system hypothesis. Infect Chemother 2015;47:12-26.

55. Ryter SW, Ma KC, Choi AMK. Carbon monoxide in lung cell physiology and disease. Am J Physiol Cell Physiol 2018;314:C211-27.

56. Dani JA. Neuronal nicotinic acetylcholine receptor structure and function and response to nicotine. Int Rev Neurobiol 2015;124:3-19.

57. Patel S. Danger-associated molecular patterns (DAMPs): the derivatives and triggers of inflammation. Curr Allergy Asthma Rep 2018;18:63.

58. Roh JS, Sohn DH. Damage-associated molecular patterns in inflammatory diseases. Immune Netw 2018;18:e27.

59. Zhu B, Zhu Q, Li N, Wu T, Liu S, Liu S. Association of serum/plasma high mobility group box 1 with autoimmune diseases: A systematic review and meta-analysis. Medicine (Baltimore) 2018;97:e11531.

60. Hernandez C, Huebener P, Schwabe RF. Damage-associated molecular patterns in cancer: a double-edged sword. Oncogene 2016;35:5931-41.

61. Venegas C, Heneka MT. Danger-associated molecular patterns in Alzheimer's disease. J Leukoc Biol 2017;101:87-98.

62. Lee KY. Pneumonia, acute respiratory distress syndrome, and early immune-modulator therapy. Int J Mol Sci 2017;18:388. https://doi.org/ 10.3390/ijms18020388.

63. Runnstrom M, Ebied AM, Khoury AP, Reddy R. Influenza-induced rhabdomyolysis. BMJ Case Rep 2018;11:e226610. https://doi.org/ 10.1136/bcr-2018-226610.

64. Wu VC, Hsueh PR, Lin WC, Huang JW, Tsai HB, Chen YM, et al. Acute renal failure in SARS patients: more than rhabdomyolysis. Nephrol Dial Transplant 2004;19:3180-2.

65. Rubin S, Eckhaus M, Rennick LJ, Bamford CG, Duprex WP. Molecular biology, pathogenesis and pathology of mumps virus. J Pathol 2015;235: 242-52.

66. Cunningham ET Jr, Kilmartin D, Agarwal M, Zierhut M. Sympathetic ophthalmia. Ocul Immunol Inflamm 2017;25:149-51.

67. Spencer R, Manivannan S, Sharouf F, Bhatti MI, Zaben M. Risk factors for the development of seizures after cranioplasty in patients that sustained traumatic brain injury: a systematic review. Seizure 2019;69:116.

68. Lava SAG, Milani GP, Fossali EF, Simonetti GD, Agostoni C, Bianchetti MG. Cutaneous manifestations of small-vessel leukocytoclastic vasculitides in childhood. Clin Rev Allergy Immunol 2017;53:439-51.

69. Rosenberg JH, Rai V, Dilisio MF, Agrawal DK. Damage-associated molecular patterns in the pathogenesis of osteoarthritis: potentially novel therapeutic targets. Mol Cell Biochem 2017;434:171-9.

70. Youn YS, Lee KY. Mycoplasma pneumoniae pneumonia in children Korean J Pediatr 2012;55:42-7.

71. Lee KY, Rhim JW, Kang JH. Kawasaki disease: laboratory findings and an immunopathogenesis on the premise of a "protein homeostasis system". Yonsei Med J 2012;53:262-75.

72. Lee KY. A unified pathogenesis for kidney diseases, including genetic diseases and cancers, by the protein-homeostasis-system hypothesis. Kidney Res Clin Pract 2017;36:132-44.

73. Kang HK, Kim C, Seo CH, Park Y. The therapeutic applications of antimicrobial peptides (AMPs): a patent review. J Microbiol 2017;55:112

74. Hutchinson JA, Burholt S, Hamley IW. Peptide hormones and lipopep tides: from self-assembly to therapeutic applications. J Pept Sci 2017;23: 82-94.

75. Nunes AT, Annunziata CM. Proteasome inhibitors: structure and func tion. Semin Oncol 2017;44:377-80.

76. Guo XJ, Thomas PG. New fronts emerge in the influenza cytokine storm. Semin Immunopathol 2017;39:541-50.

77. Wang $\mathrm{H}, \mathrm{MaS}$. The cytokine storm and factors determining the sequence 
and severity of organ dysfunction in multiple organ dysfunction syndrome. Am J Emerg Med 2008;26:711-5.

78. Simon AK, Hollander GA, McMichael A. Evolution of the immune system in humans from infancy to old age. Proc Biol Sci 2015;282:20143085.

79. Ygberg S, Nilsson A. The developing immune system - from foetus to toddler. Acta Paediatr 2012;101:120-7.

80. Leung CW, Chiu WK. Clinical picture, diagnosis, treatment and outcome of severe acute respiratory syndrome (SARS) in children. Paediatr Respir Rev 2004;5:275-88.

81. Youn YS, Lee KY, Hwang JY, Rhim JW, Kang JH, Lee JS, et al. Difference of clinical features in childhood Mycoplasma pneumoniae pneumonia. BMC Pediatr 2010;10:48.

82. Lee KY, Hong JH, Han JW, Lee JS, Lee BC, Burgner D. Features of Kawasaki disease at the extremes of age. J Paediatr Child Health 2006; 42:423-7.

83. Lau EH, Hsiung CA, Cowling BJ, Chen CH, Ho LM, Tsang T, et al. A comparative epidemiologic analysis of SARS in Hong Kong, Beijing and Taiwan. BMC Infect Dis 2010;10:50. https://doi.org/10.1186/14712334-10-50.

84. Frank C, Werber D, Cramer JP, Askar M, Faber M, Heiden MA, et al, the HUS Investigation Team. Epidemic profile of Shiga-toxin-producing Escherichia coli O104:H4 outbreak in Germany. N Engl J Med 2011; 365:1771-80.

85. Kim HS, Kim JH, Shin SY, Kang YA, Lee HG, Kim JS, Lee JK, Cho B: Fatal cases of 2009 pandemic influenza A (H1N1) in Korea. J Korean Med Sci 2011;26:22-7.

86. Ruan Q, Yang K, Wang W, Jiang L, Song J. Clinical predictors of mortality due to COVID-19 based on an analysis of data of 150 patients from Wuhan, China. Intensive Care Med 2020 Mar 3 [Epub]. https://doi.org/ 10.1007/s00134-020-05991-x.

87. Weiskopf D, Weinberger B, Grubeck-Loebenstein B. The aging of the immune system. Transplant Int 2009;22:1041-50.

88. Petrosillo N, Cataldo MA, Pea F. Treatment options for communityacquired pneumonia in the elderly people. Expert Rev Anti Infect Ther $2015 ; 13: 473-85$.

89. Nickol ME, Ciric J, Falcinelli SD, Chertow DS, Kindrachuk J. Characterization of host and bacterial contributions to lung barrier dysfunction following co-infection with 2009 pandemic influenza and methicillin resistant Staphylococcus aureus. Viruses 2019;11:116. https://oi.org/ 10.3390/v11020116.

90. Lee SC, Youn YS, Rhim JW, Kang JH, Lee KY. Early serologic diagnosis of Mycoplasma pneumoniae pneumonia: an observational study on changes in titers of specific-IgM antibodies and cold agglutinins. Medicine (Baltimore). 2016;95:e3605.

91. Chan KH, Cheng VC, Woo PC, Lau SK, Poon LL, Guan Y, et al. Serological responses in patients with severe acute respiratory syndrome coronavirus infection and cross-reactivity with human coronaviruses 229E, OC43, and NL63. Clin Diagn Lab Immunol 2005;12:1317-21.

92. Atrasheuskaya AV, Kulak MV, Neverov AA, Rubin S, Ignatyev GM. Measles cases in highly vaccinated population of Novosibirsk, Russia, 2000-2005. Vaccine 2008;26:2111-8.

93. Ryu JU, Kim EK, Youn YS, Rhim JW, Lee KY. Outbreaks of mumps: an observational study over two decades in a single hospital in Korea. Korean J Pediatr 2014;57:396-402.

94. Chiotos K, Hayes M, Kimberlin DW, Jones SB, James SH, Pinninti SG, et al. Multicenter initial guidance on use of antivirals for children with COVID-19/SARS-CoV-2. J Pediatric Infect Dis Soc 2020 Apr 22:piaa045. https://doi.org/10.1093/jpids/piaa045.

95. Ang L, Lee HW, Kim A, Lee JA, Zhang J, Lee MS. Herbal medicine for treatment of children diagnosed with COVID-19: A review of guidelines. Complement Ther Clin Pract 2020;39:101174.

96. Sanders JM, Monogue ML, Jodlowski TZ, Cutrell JB. Pharmacologic treatments for coronavirus disease 2019 (COVID-19): a review. JAMA. 2020 Apr 13 [Epub]. https://doi.org/10.1001/jama.2020.6019.

97. Barlow A, Landolf KM, Barlow B, Yeung SYA, Heavner JJ, Claassen CW, Heavner MS. Review of emerging pharmacotherapy for the treatment of coronavirus disease 2019. Pharmacotherapy 2020;40:416-37.
98. Cameron MJ, Bermejo-Martin, JE, Danesh A, Muller MK, Kelvin DJ. Human immunopathogenesis of severe acute respiratory syndrome (SARS). Virus Res 2008;133:13-9.

99. van der Poll T, Opal SM. Pathogenesis, treatment, and prevention of pneumococcal pneumonia. Lancet 2009;374:1543-56.

100. Short KR, Kroeze EJ, Fouchier RA, Kuiken T. Pathogenesis of influenzainduced acute respiratory distress syndrome. Lancet Infect Dis 2014;14: 57-69.

101. Stockman LJ, Bellamy R, Garner P. SARS: systematic review of treatment effects. PLoS Med 2006;3:e343.

102. Lansbury L, Rodrigo C, Leonardi-Bee J, Nguyen-Van-Tam J, Lim WS. Corticosteroids as adjunctive therapy in the treatment of influenza. Cochrane Database Syst Rev 2019;2:CD010406.

103. Rhim JW, Lee KY, Youn YS, Kang JH, Kim JC. Epidemiological and clinical characteristics of childhood pandemic 2009 H1N1 virus infection: an observational cohort study. BMC Infect Dis 2011;11:225.

104. Kil HR, Lee JH, Lee KY, Rhim JW, Youn YS, Kang JH. Early corticosteroid treatment for severe pneumonia caused by 2009 H1N1 influenza virus. Crit Care 2011;15:413.

105. Lee KY, Lee HS, Hong JH, Lee MH, Lee JS, Burgner D, Lee BC. Role of prednisolone treatment in severe Mycoplasma pneumoniae pneumonia in children. Pediatr Pulmonol 2006;41:263-8.

106. Youn YS, Lee SC, Rhim JW, Shin MS, Kang JH, Lee KY. Early additional immune-modulators for Mycoplasma pneumoniae pneumonia in children: An observation study. Infect Chemother 2014;46:239-47.

107. Yang EA, Kang HM, Rhim JW, Kang JH, Lee KY. Early corticosteroid therapy for Mycoplasma pneumoniae pneumonia irrespective of used antibiotics in children. J Clin Med 2019;8:E726. https://doi.org/ $10.3390 / \mathrm{jcm} 8050726$.

108. Lee KY. Pediatric respiratory infections by Mycoplasma pneumoniae. Expert Rev Anti Infect Ther 2008;6:509-21.

109. Huang C, Wang Y, Li X, Ren L, Zhao J, Hu Y, et al. Clinical features of patients infected with 2019 novel coronavirus in Wuhan, China. Lancet 2020;395:497-506.

110. Lee KY, Rhim JW, Kang JH. Early preemptive immune modulators (corticosteroids) for severe pneumonia patients infected with SARSCoV-2. Clin Exp Pediatr 2020;63:117-8.

111. Mehta P, McAuley DF, Brown M, Sanchez E, Tattersall RS, Manson JJ: HLH Across Speciality Collaboration, UK. COVID-19: consider cytokine storm syndromes and immunosuppression. Lancet 2020;395: 1033-4.

112. Beth Russell, Charlotte Moss, Anne Rigg, Mieke Van Hemelrijck. COVID-19 and treatment with NSAIDs and corticosteroids: should we be limiting their use in the clinical setting? Ecancermedicalscience 2020; 14:1023.

113. Veronese N, Demurtas J, Yang L, Tonelli R, Barbagallo M, Lopalco P, et al. Use of corticosteroids in coronavirus disease 2019 pneumonia: a systematic review of the literature. Front Med (Lausanne). 2020;7:170.

114. Blum CA, Nigro N, Briel M, Schuetz P, Ullmer E, Suter-Widmer I, et al. Adjunct prednisone therapy for patients with community-acquired pneumonia: a multicentre, double-blind, randomised, placebo-controlled trial. Lancet 2015;385:1511-8.

115. Torres A, Sibila O, Ferrer M, Polverino E, Menendez R, Mensa J et al. Effect of corticosteroids on treatment failure among hospitalized patients with severe community-acquired pneumonia and high inflammatory response: A randomized clinical trial. JAMA 2015;313:677-86.

116. Jiang S, Liu T, Hu Y, Li R, Di X, Jin X, et al. Efficacy and safety of glucocorticoids in the treatment of severe community-acquired pneumonia: a meta-analysis. Medicine 2019;98:e16239.

117. Tamura A, Matsubara K, Tanaka T, Nigami H, Yura K, Fukaya T. Methylprednisolone pulse therapy for refractory Mycoplasma pneumoniae pneumonia in children. J Infect. 2008;57:223-8.

118. Tsunoda R, Usui J, Hoshino J, Fujii T, Suzuki S, Takaichi K, et al. Corticosteroids pulse therapy and oral corticosteroids therapy for IgA nephropathy patients with advanced chronic kidney disease: results of a multicenter, large-scale, long-term observational cohort study. BMC Nephrol 2018;19:222. 
119. Antonio R, Silvia M. Immunosuppression drug-related and clinical manifestation of coronavirus disease 2019: a therapeutical hypothesis. Am J Transplant 2020 Apr 3 [Epub]. https://doi.org/10.1111/ajt.15905.

120. Spezzani V, Piunno A, Iselin HU. Benign COVID-19 in an immunocompromised cancer patient; the case of a married couple. Swiss Med Wkly 2020;150:w20246.
121. Ahn JY, Sohn Y, Lee SH, Cho Y, Hyun JH, Baek YJ, et al. Use of convalescent plasma therapy in two COVID-19 patients with acute respiratory distress syndrome in Korea. J Korean Med Sci 2020;35:e149.

122. Shen C, Wang Z, Zhao F, Yang Y, Li J, Yuan J, et al. Treatment of 5 critically ill patients with COVID-19 with convalescent plasma. JAMA 2020;323:1582. 